\title{
SHAKE TABLE TESTS FOR THE SEISMIC FRAGILITY EVALUATION OF HOSPITAL ROOMS
}

\author{
Cosenza E. ${ }^{1}$, Di Sarno L. ${ }^{*}$, Maddaloni G. ${ }^{3}$, Magliulo G. ${ }^{1}$, Petrone C. ${ }^{1}$, Prota A. ${ }^{1}$ \\ ${ }^{1}$ Department of Structures for Engineering and Architecture, University of Naples, Italy \\ ${ }^{2}$ Department of Engineering, University of Sannio, Italy \\ ${ }^{3}$ Department of Technology, University of Naples Parthenope, Italy
}

\begin{abstract}
Health care facilities may undergo severe and widespread damage that impairs the functionality of the system when it is stricken by an earthquake. Such detrimental response is emphasized either for the hospital buildings designed primarily for gravity loads or without employing base isolation/supplemental damping systems. Moreover these buildings need to warrant operability especially in the aftermath of moderate-to-severe earthquake ground motions.

The provisions implemented in the new seismic codes allow obtaining adequate seismic performance for the hospital structural components; nevertheless, they do not provide definite yet reliable rules to design and protect the building contents. To date, very few experimental tests have been carried out on hospital buildings equipped with nonstructural components as well as building contents.

The present paper is aimed at establishing the limit states for a typical health care room and deriving empirical fragility curves by considering a systemic approach. Towards this aim, a full scale three-dimensional model of an examination (out patients consultation) room is constructed and tested dynamically by using the shaking table facility of the University of Naples, Italy. The sample room contains a number of typical medical components, which are either directly connected to the panel boards of the perimeter walls or behave as simple free-standing elements. The outcomes of the comprehensive shaking table tests carried out on the examination room have been utilized to derive fragility curves based on a systemic approach.
\end{abstract}

\section{KEYWORDS}

Hospital building contents, Nonstructural components, Shake table test, Seismic fragility, Fragility curve.

\footnotetext{
* Corresponding author: Luigi Di Sarno, Department of Engineering, University of Sannio, 80121, Benevento, Italy. phone +390824305566, fax +390824325246. email: ldisarno@unisannio.it
} 


\section{INTRODUCTION}

The modern earthquake engineering has focused on the performance-based design of newly-built structures and the assessment of existing buildings and bridges (e.g. [1]). Limit states (LSs), have thus been defined, either qualitatively or quantitatively, and evaluated through post-earthquake surveys, experimental tests and numerical simulations. In a broader socio-economic context, LSs may be related to repair costs (e.g., expressed as a percentage of replacement value) that are in excess of a desired amount, opportunity losses, morbidity and mortality. It applies to performance levels of structural, non-structural and contents $[2,3]$. The harmonization of the performance levels between structural and nonstructural systems is vital. The evaluation of the limit states and, in turn, the performance objectives of new and existing buildings depends on their use and occupancy. The seismic performance levels of critical facilities, such as hospital buildings and emergency units, are significantly dependent on the functionality of the system. Thus, resilient health care facilities should prevent the disruption of their functionality during post-disaster emergency (e.g. [4], among many others). It is estimated that $97 \%$ of earthquake related injuries occur within the first 30 minutes following the main shock [5], thus it is of paramount importance that hospitals remain operational and continue providing fundamental health services following the disasters. A typical emergency response of hospitals in the aftermath of an extreme event, such as earthquakes, is pictorially displayed in Figure 1. The pre-accident capability is also shown in the figure as a benchmark for the needs of treatment demand caused by the occurrence of the seismic event.

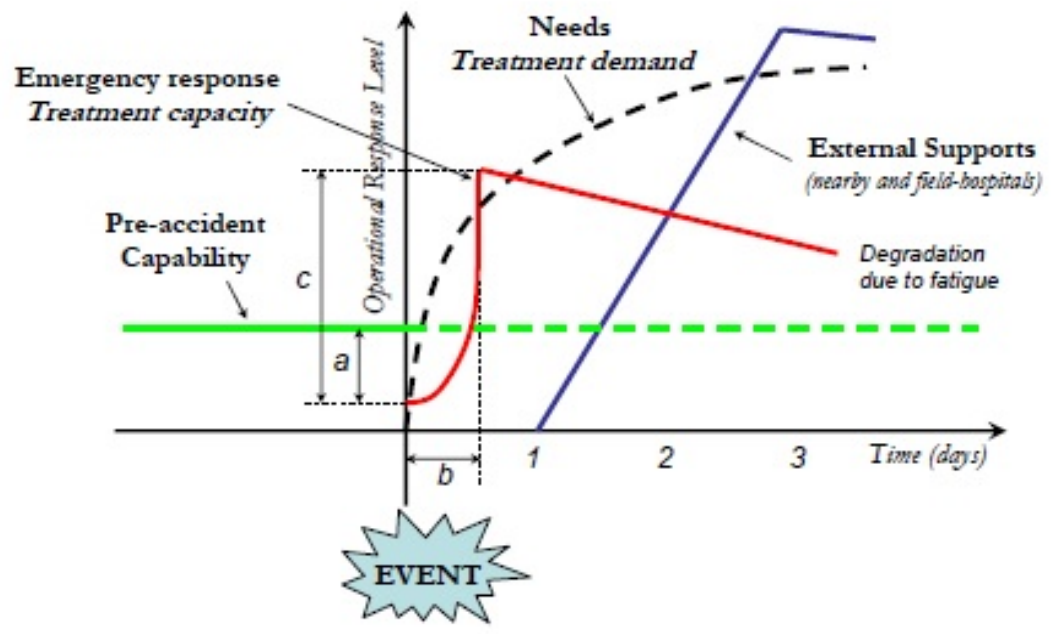

Figure 1. Typical emergency response of hospitals in the aftermath of an extreme event, such as an earthquake [6].

Moreover, the occurrence of non-structural damage, encompassing primarily failure of windows, doors, partition walls, suspended ceilings, lighting and floor coverings, should be inhibited as it may affect detrimentally the emergency response and, in turn, it may cause the medical evacuations [7]. Additionally, the architectural, mechanical and electrical components account for nearly $45 \%$ of the capital cost [3]; thus their failure may cause massive losses for the social communities. Notwithstanding, surveys carried out in the aftermath of recent major earthquakes world-wide [810], e.g. the 2008 Sichuan (China), the 2009 L'Aquila (Italy), the 2010-2011 Darfield-Christchurch (New Zealand), the 2011 Van (Turkey) and the 2012 Emilia-Romagna (Italy) earthquakes, have emphasized the inadequate performance of existing hospitals. Widespread non-structural damage was detected primarily in buildings that were not compliant with modern seismic codes. Nevertheless, the failure of services and building contents was surveyed both in newly built hospital and in structures designed only for gravity loads. Figure 2 displays the extensive damage to the building contents observed in the aftermath of the 2011 Van (Turkey) earthquake in the Yüzüncü 
Yil University - Faculty of Medicine Hospital. The losses of internal and external services as well as the damage to back-up systems were extensive, thus the nearly 500-beds hospital had to be completely closed and emergency response facilities relocated.
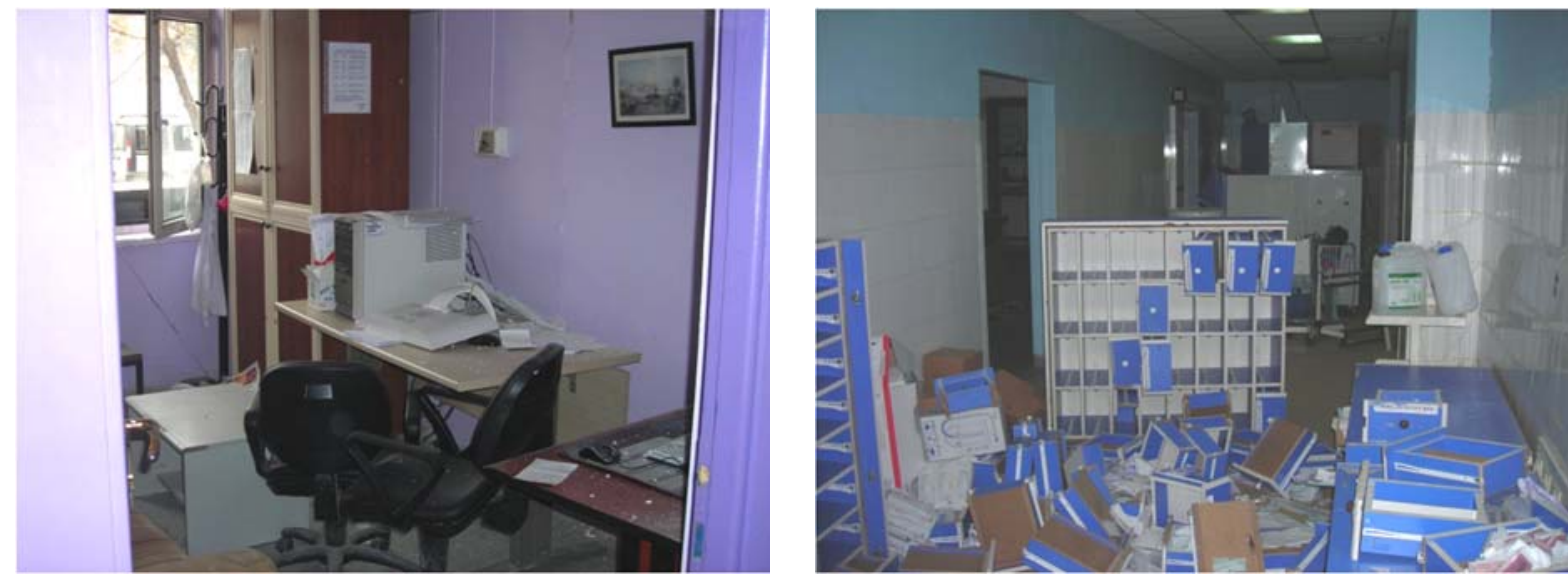

Figure 2. Damage to the building contents surveyed in the aftermath of the 2011 Van (Turkey) earthquake in the Yüzüncü Yil University - Faculty of Medicine Hospital.

The above discussion demonstrates that there is still an urgent need to further investigate the earthquake performance of medical equipment and typical hospital components.

\subsection{State of the art research}

Recently, few studies have been initiated to analyze the seismic performance of a variety of furniture items, medical appliances and service utilities of typical hospital buildings and pharmacies. Full scale shake table tests were carried out on a base-isolated four story RC hospital structure $[11,12]$. Recorded near-fault strong motions and artificial long-period, long duration records were used for the experimental tests. Significant reductions of the floor accelerations were observed for the base-isolated structure subjected to near-fault ground motions. Operational and functionality limit states of the healthcare buildings were significantly augmented if compared with the fixed-base case. The use of base-isolation was not sufficient to ensure the hospital service in case the long-period motions were employed. Under such loading conditions, significant motions of furniture items and medical appliances supported by casters were detected. Large sliding displacements and occasional collisions of furniture items and medical appliances with other furniture components or against the supports were observed at resonance. To ensure the functionality of the medical facility it was recommended to securely lock the casters of furniture and medical appliances. Kuo et al. [13] performed shake table tests on typical medicine shelves and contents placed in pharmacies, which are one of the critical departments for delivering postearthquake emergency care. Using sinusoidal waveforms, it was found that the objects fell from the lower shelves of the stock and tablet medicine shelf units. Conversely, more objects fell from the upper shelves of the powder medicine shelf unit. Initiation of overturned shelves and fallen objects scattered on floors was caused by the peak acceleration of the input excitation. After the initiation, the response is influenced simultaneously by acceleration and velocity.

Experimental tests on composite hospital rooms have also been carried out at the Structural Engineering and Earthquake Simulation Laboratory (SEESL) at the University of Buffalo (UB) in the USA, using the Nonstructural Component Simulator (UB-NCS), which is a modular and versatile two-level structure for experimental seismic performance evaluation of full-scale acceleration and displacement sensitive nonstructural components under realistic floor motions expected within multi-story buildings [14]. The bi-directional shake table tests aimed at evaluating the earthquake effects on typical medical equipment and other nonstructural components in hospitals. The research focused primarily on steel-stud gypsum partition wall, lay-in suspended 
ceiling system, fire protection sprinkler piping systems. Similarly, the tests on the 5-story building, at the outdoor UCSD-NEES shake table facility in San Diego, California, deals with a broad array of nonstructural components, such as functioning passenger elevator, stairs, exterior walls, interior partition walls, piping, Heating, Ventilation and Air Conditioning (HVAC), ceiling, sprinklers, building contents, as well as passive and active fire systems [15]. A number of experimental tests on the shake table dealing with medical laboratory components, such as low-temperature refrigerators, heavy incubators, freezers, microscopes and lighter computer equipment located on desks and shelves, were also carried out at the University of California, Berkeley (e.g. [16, 17]). Emphasis was on the derivation of fragility curves for earthquake loss estimation and formulation of retrofitting measures.

In [18] the identification of the essential equipment component in critical facilities is discussed. The performance of different equipment during past earthquakes is also described, while in $[19,20]$ methodologies for the evaluation of the seismic vulnerability of critical facilities are proposed. Achour [20] studied the stability of free standing equipment, focusing on medical equipment (e.g. nurse tables and cabinets), using both experiment and theoretical modelling. The fragility curves of equipment, which are placed on top of a nurse table and shelves/cabinets, are also provided. Zhang and Makris [21] comprehensively studied, through the analytical method, the stability of free standing blocks subjected to trigonometric pulses; evidencing the complex behavior of such blocks. In the last years, following the quoted experimental and numerical studies on nonstructural components, technical committees are developing standard provisions for nonstructural components.

The state of California is a reference on the topic [8, 22, 23]. The Hospital Seismic Safety Act (HSSA), enacted following the 1971 San Fernando Earthquake, identified deficiencies in building codes and established new seismic safety standards, although it addressed merely new constructions. The 1994 Northridge (California) earthquake caused significant damage to pre-HSSA buildings and nonstructural damage to pre- and post-HSSA buildings. The latter earthquake initiated the SB1953 [24], the hospital seismic retrofit program, i.e. an amendment to the HSSA. The steps of the aforementioned program are: the evaluation of the hospital seismic retrofit issue, a database implementation of the hospital building stock, the retrofit to prevent collapse and loss of life and the retrofit to provide continued operation after an earthquake. The regulations developed as a result of SB1953 become effective upon approval by the California Building Standard Commission. According to the 2007 California Building Code (CBC), the requirements for nonstructural components in or attached to occupancy IV category structures are: seismic qualification of mechanical and electrical equipment (designed per chapter 13 of ASCE 7 [25] with importance factor $\mathrm{I}_{\mathrm{p}}>1.0$ ); manufacturer's seismic certifications for architectural, mechanical and electrical components, supports and attachments. The seismic qualification can be attained by: test on a shake table [26, 27], analytical method using dynamic characteristics and forces, experience data (i.e. historical data demonstrating acceptable seismic performance), detailed analyses providing equivalent safety. The whole procedure concerning the design and the application of nonstructural components provides firstly that the engineer states the applicable requirements for the designated seismic system on construction documents, secondly the manufacturer provides the certificate of compliance, thirdly a California Structural Engineer reviews and accepts the certification and finally there is the approval of Building Official.

\subsection{Research aim and objectives}

Based on the motivations included in the previous paragraphs, the present paper illustrates the preliminary results of comprehensive shake table experimental tests carried out on a full-scale examination (out patients consultation) room unit equipped with typical architectural finishing, freestanding furniture items, desktop computer and medical equipment. The results of the investigations included in Section 1.1 are mainly based on either past earthquake data or numericalanalytical models; moreover, they generally do not encompass the specific components/equipment 
assessed herein. Additionally, the present study introduces the novel systemic approach to evaluate the seismic fragility of the components included in the consultation room. Such an approach accounts for the convolution of the fragilities of the single components analyzed experimentally on the shaking table.

The study aims at evaluating of the seismic performance of hospital room contents, such as freestanding cabinets, through the experimental method. Vulnerable freestanding components and medical appliances were identified on the basis of survey questionnaires and simplified evaluation forms compiled by hospital staff for numerous healthcare facilities world-wide [8, 10, 28]. Examination rooms are departments that are critical to their functioning in healthcare facilities [24, 29]. Thus, such rooms were selected as representative layouts for the experimental seismic performance assessment of the core units of hospital buildings. Different configurations were analyzed and relevant limit states identified for each component and the whole room unit. Acceleration time histories with increasing amplitudes were used to derive seismic fragility curves for the whole medical room, according to a systemic approach.

\section{RESEARCH METHOD}

\subsection{Test setup and specimens}

The seismic tests on hospital building contents are carried out by the earthquake simulator system available at the laboratory of Structures for Engineering and Architecture Department of University of Naples Federico II, Italy. The system consists of two $3 \mathrm{~m}$ x $3 \mathrm{~m}$ square shake tables. Each table is characterized by two degrees of freedom along the two horizontal directions. The maximum payload of each shake table is $200 \mathrm{kN}$ with a frequency ranging between 0 and $50 \mathrm{~Hz}$, acceleration peak equal to $1 \mathrm{~g}$, velocity peak equal $1 \mathrm{~m} / \mathrm{sec}$ and total displacement equal to $500 \mathrm{~mm}( \pm 250 \mathrm{~mm})$. A single shake table is utilized for the present experimental campaign.

A steel single-story framed system was designed (Figure 3) with the purpose of simulating the seismic effects on the medical contents of a typical hospital room. To simulate the effects of the earthquake at different floors on a hospital building, the geometry of the test frame was designed to prevent the onset of the resonance. As a result, the steel frame possesses a large lateral stiffness. The layout of the model consists of a $2.42 \mathrm{~m} \times 2.71 \mathrm{~m} \mathrm{x} 2.72 \mathrm{~m}$ test fixture of S275 steel material with concentric V-bracings (see Figure 3). The sample frame employs H-shaped columns (HE220A profile) and beams (HE180A profile); the connections are bolted. A horizontal double warping frame made of U-section steel profiles (UPN100) is bolted to the beams of the test frame (HE180A). Concentric V-bracing systems are also used to provide high lateral stiffness; bracing systems are made of steel U-section (UPN160). Further details on the steel test setup are included in [30].

A finite element model (FEM) of the sample steel braced frame is implemented in the computer program SAP2000 [31]. Elastic "beam" elements are used to simulate the response of the beamcolumns of the braced frames. The FEM model is employed to estimate the periods of vibration associated to the translational modes along the orthogonal directions; such period is about $0.02 \mathrm{~s}$. The frame can thus be classified as rigid lateral resisting system. The total weight of the sample structure is $19.2 \mathrm{kN}$.

A typical hospital examination (out patients consultation) room background is reproduced within the sample steel frame. Plasterboard partitions and ceilings are mounted; linoleum sheets are also installed to cover both the floor and a large portion of the internal partitions. An overhead light and a ray film viewer are also installed in the room. 

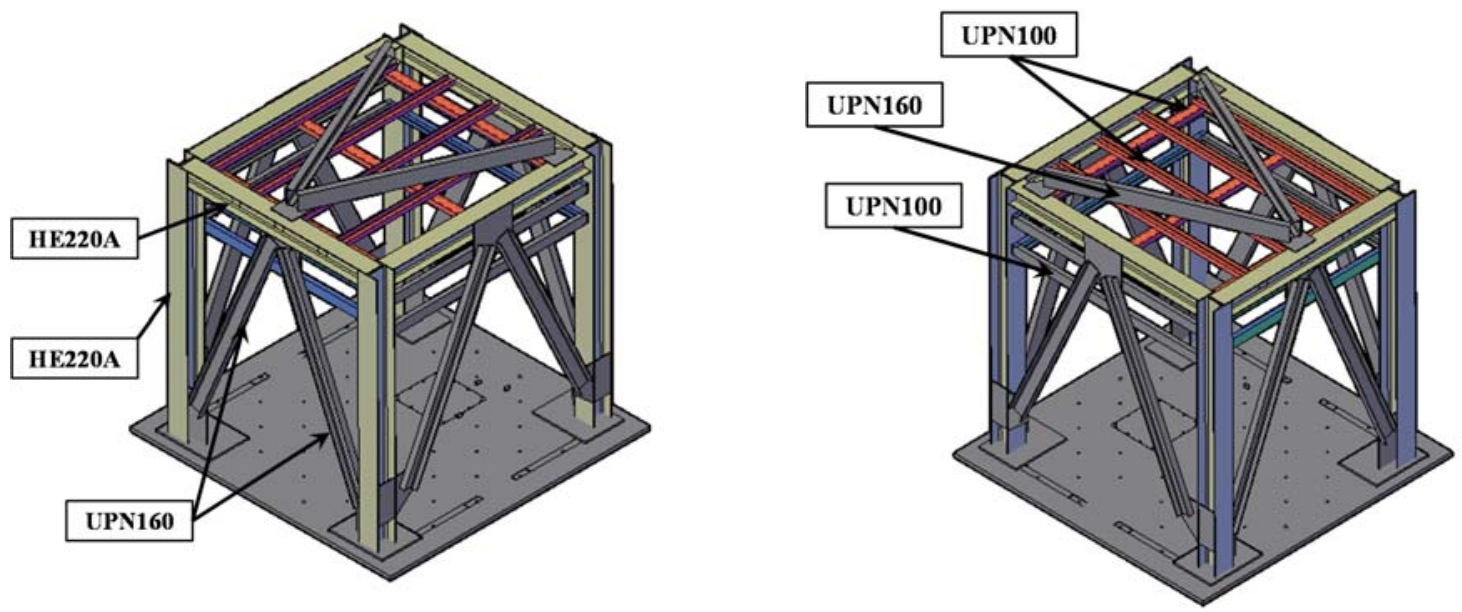

Figure 3. Global perspective of the test setup.

The building contents used for the examination room include: (a) a hospital medicine cabinet

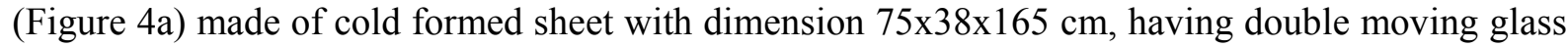
doors with locker and four mobile glass shelves; (b) a hospital medicine cabinet (Figure 4b) made of cold formed sheet with dimension $53 \times 36 \times 139 \mathrm{~cm}$, having single moving glass door with locker and four mobile glass shelves; (c) a desktop computer (monitor, case, keyboard and mouse); (d) a desk made of a steel pipes frame and a wooden desktop and having two drawers with locker (Figure 4c). The mass of the two cabinets is $20 \mathrm{~kg}$ and $15 \mathrm{~kg}$ for the single-window and the double-window cabinets, respectively; the mass of the desk is $31.6 \mathrm{~kg}$. Cabinet contents with different slenderness as glass bottles, flasks and test tubes, are placed in the cabinets to simulate the actual conditions of a typical hospital room. Different mass distributions are also selected to distribute such contents in the single- and double-window cabinets (see Section 2.3).

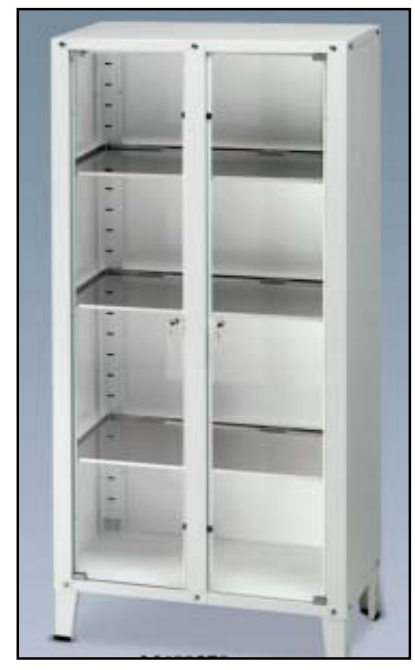

(a)

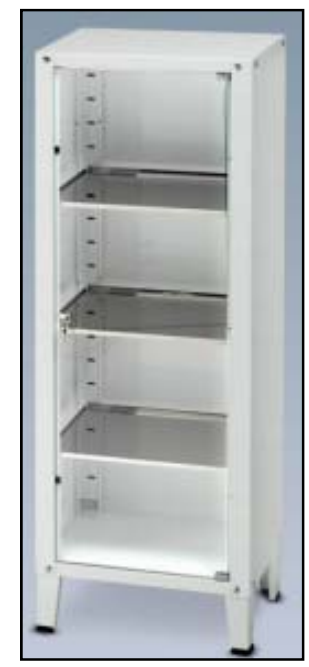

(b)

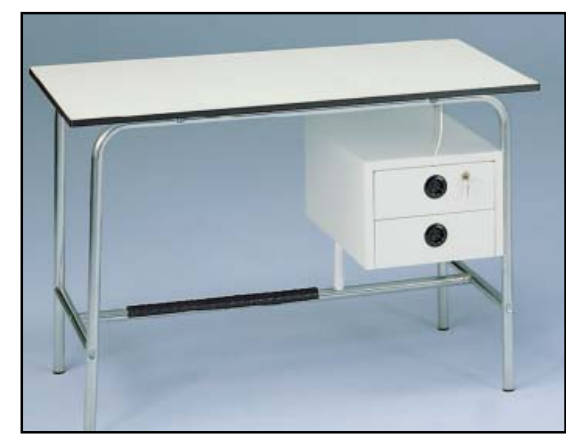

(c)

Figure 4. Tested hospital building contents: (a) double-window cabinet, (b) single-window cabinet and (c) desk.

High quality digital accelerometers are used to monitor the response of the hospital building contents. Four accelerometers are placed at the base, i.e. at the lowest shelf level, and at the top of the front side of each cabinet; one accelerometer is positioned at the top of the desk and at the top of the monitor; one accelerometer records the acceleration at the shake table level. 


\subsection{Input and testing protocol}

To investigate the seismic behavior of the hospital room, a suite of accelerograms, used as input for the unidirectional horizontal shakings (Figure 5), are adequately selected to match a target response spectrum, provided by the ICBO-AC156 code "Acceptance criteria for seismic qualification testing of nonstructural components" [32].

The first step consists in the definition of the target spectrum or required response spectrum (RRS). According to AC 156, the RRS is obtained as a function of the design spectral response acceleration at short periods, SDS, depending on the site soil condition and the mapped maximum earthquake spectral acceleration at short periods (for more details see section 6.5 in ICBO-AC156). The procedure is performed for a Required Response Spectrum corresponding to $\mathrm{SDS}_{\mathrm{DS}}=1.50 \mathrm{~g}$. As recommended by the AC156 code procedure, a baseline signal is defined starting from nonstationary broadband random excitations having an energy content ranging from 1.3 to $33.3 \mathrm{~Hz}$ and one-sixth-octave bandwidth resolution. The total length of the input motion is 30 seconds. Then, the signal is enhanced by introducing wavelets using the spectrum-matching procedure of the RSP Match program [33]. The acceleration response spectrum is shown in Figure 5b. The matching is approximately obtained, over the frequency range from 1.3 to $33.3 \mathrm{~Hz}$, according to AC 156. To obtain a drive motion compatible with the shake table velocity and displacement limits, the so obtained matched record is high passed filtered for frequencies larger than $1.0 \mathrm{~Hz}$. Figure 5 shows the obtained time history acceleration, its elastic response spectra, the RRS corresponding to SDS equal to $1.50 \mathrm{~g}$ and the RRS scaled to $130 \%$.

The procedure is performed as mentioned for a RRS corresponding to $\mathrm{SDS}=1.50 \mathrm{~g}$; the so obtained record is then scaled to match different intensity levels. SDs ranges between $0.15 \mathrm{~g}$ and $1.80 \mathrm{~g}$ in the different tests of the test campaign described in Section 2.3. Additional information on testing input and testing protocol is present in [30,34].

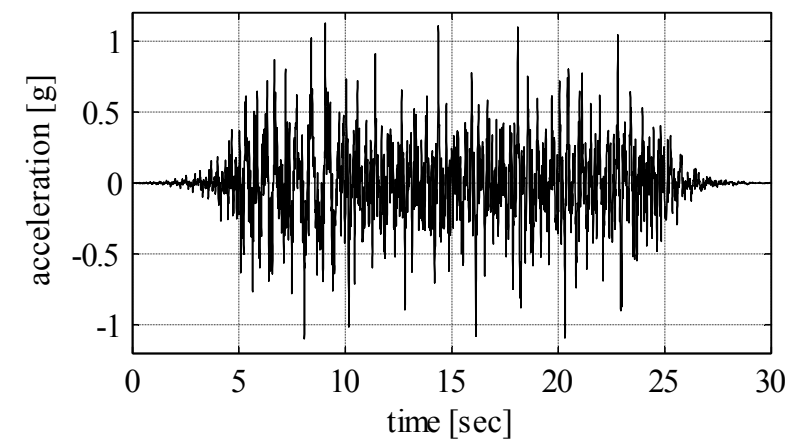

(a)

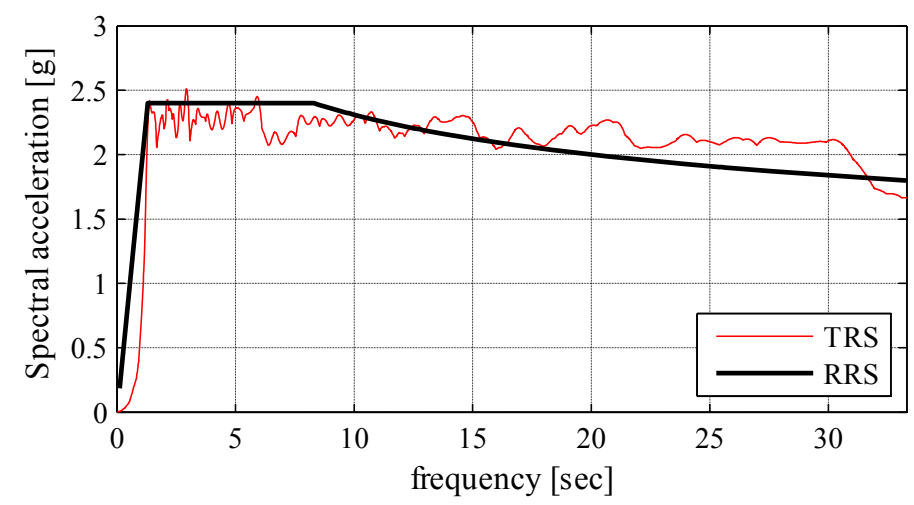

(b)

Figure 5. Earthquake time history and spectra for a level of shaking corresponding to SDS equal to 1.50g: (a) acceleration time-history; (b) input accelerogram spectrum (TRS) and Required Response Spectrum (RRS). 
Preliminarily, system identification tests were also carried out using two single-axis loading protocols: low-amplitude sine-sweep and white noise with low-acceleration, i.e. with root-meansquare intensity limited to $0.05 \pm 0.01 \mathrm{~g}$, in compliance with the provisions included in [35].

\subsection{Test program}

The definition of a typical condition for the sample cabinets is a crucial issue of the research study. Different variables, related to the arrangement of the contents on the different shelves and to the position of the cabinets with respect to the wall behind, are considered. A few variables are investigated in the six test groups of the undertaken test campaign (Table I).

Test group 100 assesses the behavior of the cabinet with an equivalent mass, i.e. sand inserted in boxes, at each shelf of the cabinets. $6 \mathrm{~kg}$ mass and $4 \mathrm{~kg}$ mass is added for each shelf of the doublewindow cabinet (Figure 6a) and single-window cabinet, respectively; the mass amount is representative of the mass of typical contents inserted in such a cabinet. The use of the equivalent mass is required in order to investigate the behavior of the cabinets with different contents on their shelves; the contents are simulated through the use of sand boxes in order to avoid damaging and replacing the contents after each shaking.

Test group 200 investigates the behavior of the cabinets with a decreasing mass distribution along the height. From the base to the top, on the four shelves of the double-window cabinet, $6 \mathrm{~kg}, 4 \mathrm{~kg}, 4$ $\mathrm{kg}$ and $2 \mathrm{~kg}$ masses are placed (Figure 6b). Instead, on the four shelves of the single-window cabinet $4 \mathrm{~kg}, 2 \mathrm{~kg}, 2 \mathrm{~kg}$ and $0 \mathrm{~kg}$ masses are placed. The aim is to investigate the behavior of cabinets in which, as typically suggested, the heaviest contents are placed at the lowest shelves.

Typical glass contents are tested in test group 300, as shown in Figure 6c. The contents are equally placed on the different shelves of each cabinet. Glass bottles with different dimensions, i.e. $100 \mathrm{ml}$, $250 \mathrm{ml}$ and $500 \mathrm{ml}$, are placed in the double-window cabinet whereas $250 \mathrm{ml}$ and $100 \mathrm{ml}$ flasks, test tubes and glass beaker are placed in the one-window cabinet. They are filled with colored sand, that simulates the presence of water. In this test group the behavior of real contents is also investigated

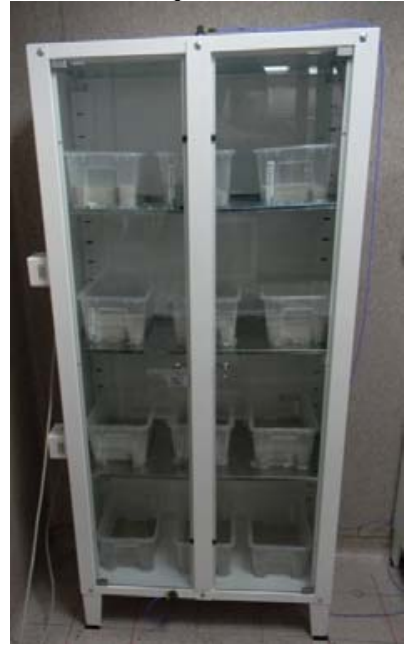

(a)

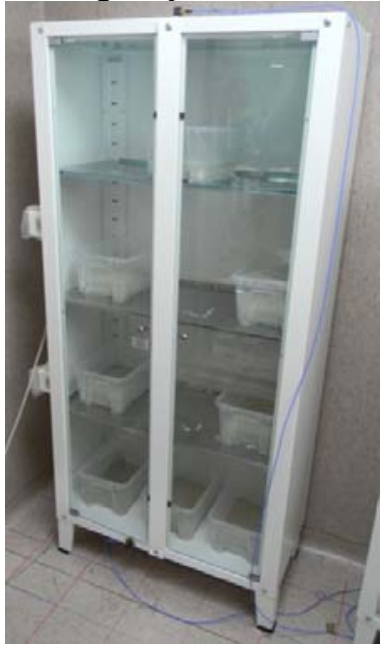

(b)

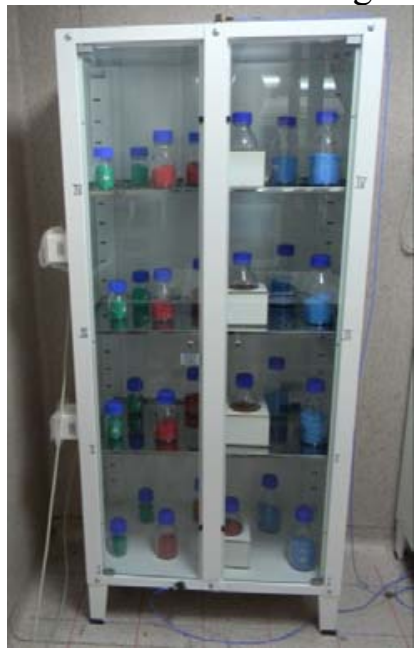

(c)

Figure 6. Double-window cabinet in (a) test groups 100 and 400, (b) test groups 200 and 500 and in (c) test groups 300 and 600 .

In Figure 7a the plan configuration of the different components in test groups 100, 200 and 300 is shown. A different plan configuration is defined in test groups 400, 500 and 600 (Figure $7 \mathrm{~b}$ ). The different components are arranged in such a way that the different components are shaken along the orthogonal direction, given the unidirectional input motion. In test groups 400, 500 and 600 the same content mass configurations of test groups 100, 200 and 300, respectively, are chosen. 
This work will focus primarily on the results carried out by applying the unidirectional loading component. Nevertheless, further investigation is ongoing and bidirectional input motion has been considered. This issue does not seem to be of significant detriment to the results presented herein.

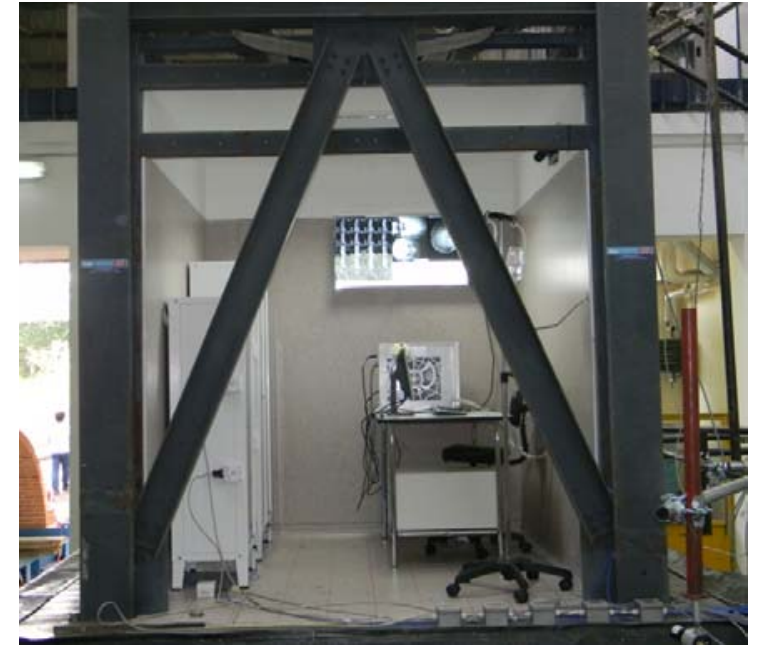

(a)

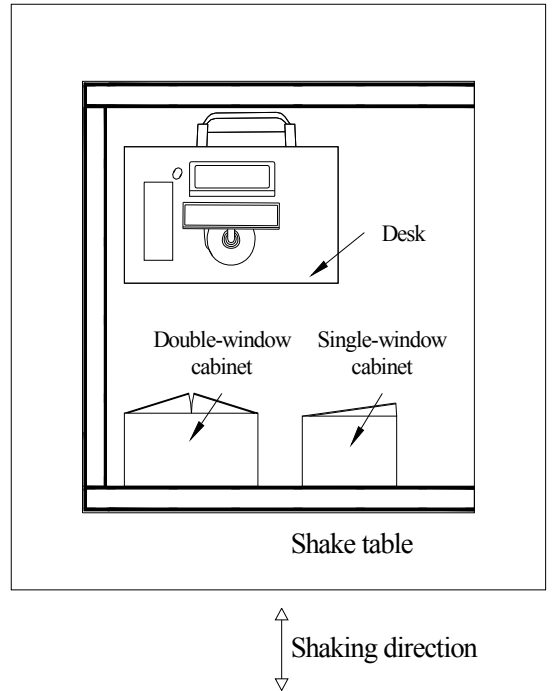

(c)

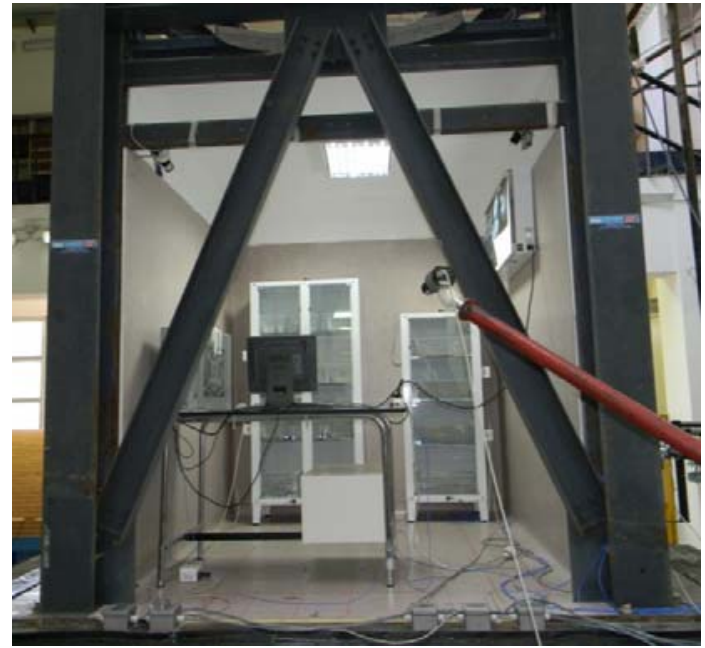

(b)

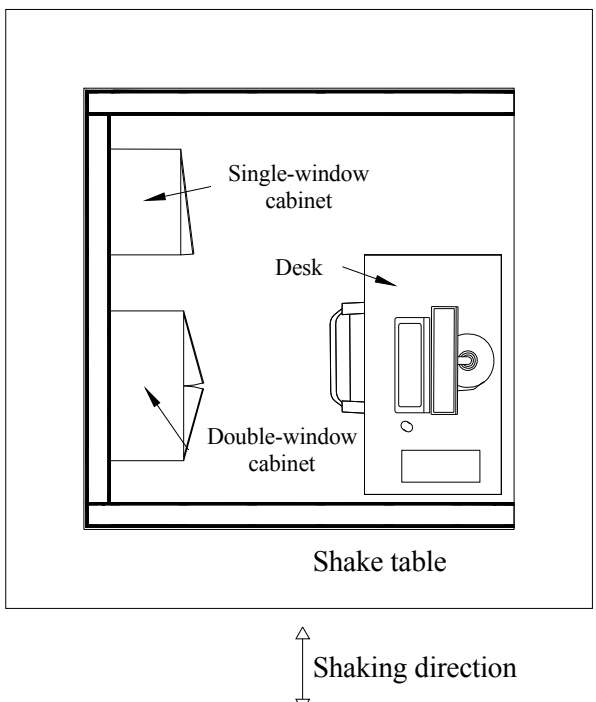

(d)

Figure 7. Photo and plan view of the test setup: (a) and (c) configuration 1, adopted in test groups 100, 200 and 300 and (b) and (d) configuration 2, adopted in test groups 400, 500 and 600.

Two test groups, i.e. 110 and 120, investigate the influence of the distance between the cabinets and the wall behind on the seismic response of the cabinets. The other parameters, e.g. contents mass, are the same as the ones adopted in test group 100. A $10 \mathrm{~cm}$ and a $15 \mathrm{~cm}$ cabinet-to-wall gap is defined in test groups 110 and 120, while in test group 100 the gap is $2 \mathrm{~cm}$. 
Table I. Test program definition.

\begin{tabular}{|c|c|c|c|}
\hline $\begin{array}{l}\text { Test } \\
\text { group }\end{array}$ & $\begin{array}{c}\text { Plan } \\
\text { configuration }\end{array}$ & Cabinets contents & $\begin{array}{c}\text { Cabinet-to-wall distance } \\
{[\mathrm{cm}]}\end{array}$ \\
\hline 100 & 1 & Equivalent mass uniformly distributed along the height & 2 \\
\hline 110 & 1 & Equivalent mass uniformly distributed along the height & 10 \\
\hline 120 & 1 & Equivalent mass uniformly distributed along the height & 15 \\
\hline 200 & 1 & Equivalent mass non uniformly distributed along the height & 2 \\
\hline 300 & 1 & Typical glass contents uniformly distributed along the height & 2 \\
\hline 400 & 2 & Equivalent mass uniformly distributed along the height & 2 \\
\hline 500 & 2 & Equivalent mass non uniformly distributed along the height & 2 \\
\hline 600 & 2 & Typical glass contents uniformly distributed along the height & 2 \\
\hline
\end{tabular}

For the whole test campaign it is chosen to lock the cabinet windows and do not to restrain the cabinet to the wall behind, which is representative of the typical conditions in European hospitals. Each test group provides a set of shakings with increasing intensity, according to Section 2.2. A total number of 63 shakings are performed during the whole test campaign. After each shaking the different components are relocated in their original condition.

\subsection{Damage scheme definition}

A damage scheme is defined in order to correlate the visual damage to the achievement of a given damage state. Three damage states are defined, i.e. Damage State 1 (DS1), Damage State 2 (DS2) and Damage State 3 (DS3). The damage state definitions are strictly related to the loss that a given damage state would cause, as indicated in Table II. In particular the correlation between each damage state and the loss should take into account of [35]: (a) the life loss (Deaths), (b) the direct economic loss due to the repair or replacement of the components (Damage) and (c) the occupancy or the service loss (Downtime). The onset of DS1 implies the need of repairing/repositioning the damaged component in its original condition; DS2 means that part of the component is damaged and it must be removed and replaced; DS3 implies that the life safety is threatened and the component needs to be totally replaced. Damage is observed after each test inspecting the tested specimen. The recorded damage in each component is then correlated to one of the three damage states defined above through the use of a damage scheme (Table II). The level of damage required to reach a limit state is defined for each damage typology of each system component (i.e. cabinet, desk and contents). If possible, the damage type is defined quantitatively. The damage state achieved by the whole specimen is the maximum damage state recorded among the different components. This process is required for the definition the fragility curves described in Section 3.3. After each test, damage is observed inspecting the specimen components and consequently an appropriate damage table is compiled (see Table VIII in Appendix) by visual inspectors. 
Table II. Damage scheme for the correlation of the visual damage to the damage state.

\begin{tabular}{|c|c|c|c|c|}
\hline & & Damage state 1 & Damage state 2 & Damage state 3 \\
\hline Component & $\begin{array}{l}\text { Damage } \\
\text { typology }\end{array}$ & $\begin{array}{l}\text { Operational } \\
\text { interruption }\end{array}$ & $\begin{array}{c}\text { Need to replace damaged } \\
\text { part of the components }\end{array}$ & $\begin{array}{c}\text { Need to replace the whole } \\
\text { component and/or threat for life } \\
\text { safety }\end{array}$ \\
\hline \multirow{5}{*}{ Cabinet } & $\begin{array}{c}\text { Residual } \\
\text { displacement }\end{array}$ & $\begin{array}{l}\text { Displacement } \\
\text { larger than } 2 \mathrm{~cm}\end{array}$ & - & - \\
\hline & \multirow{3}{*}{ Collapse } & Screw loosening & Collapse of one support & Collapse of more than one support \\
\hline & & $\begin{array}{c}\text { Residual } \\
\text { displacement in } \\
\text { shelves less than } \\
\text { L/500 }\end{array}$ & $\begin{array}{l}\text { Permanent displacement in } \\
\text { shelves larger than L/500 }\end{array}$ & Shelves collapse \\
\hline & & Window opening & Window locking & Window collapse \\
\hline & Overturning & Rocking & Hammering (with damage) & Overturning \\
\hline \multirow{3}{*}{ Desk } & $\begin{array}{c}\text { Residual } \\
\text { displacement }\end{array}$ & $\begin{array}{l}\text { Displacement } \\
\text { larger than } 4 \mathrm{~cm}\end{array}$ & - & - \\
\hline & \multirow{2}{*}{ Collapse } & Screw loosening & Collapse of one support & Collapse of more than one support \\
\hline & & Drawer opening & Drawer slipping out of rail & Desk collapse or overturning \\
\hline Content & - & Displacement & Collapse (less than $10 \%$ ) & Collapse (more than $10 \%$ ) \\
\hline
\end{tabular}

\section{RESULTS AND DISCUSSION}

\subsection{Dynamic identification}

Random vibration excitations are performed in order to dynamically identify the different tested components. In particular, before the execution of each of the test group campaign, different random excitations at different intensity levels are executed (Table III). Test 1001-1004 are performed before test group 100, test 2001-2002 before test group 200, and so forth. 
Table III. Random vibration tests ID, amplitude and root mean square.

\begin{tabular}{|c|c|c|c|c|}
\hline & Test ID & Typology & Amplitude [g] & Root mean square $[\mathrm{g}]$ \\
\hline \multirow{4}{*}{ § } & 1001 & Random & 0.06 & 0.02 \\
\hline & 1002 & Random & 0.11 & 0.03 \\
\hline & 1003 & Random & 0.22 & 0.05 \\
\hline & 1004 & Random & 0.27 & 0.06 \\
\hline \multirow{2}{*}{ ঠి } & 2001 & Random & 0.10 & 0.03 \\
\hline & 2002 & Random & 0.20 & 0.05 \\
\hline \multirow{3}{*}{ ঠ্ঠি } & 3000 & Random & 0.07 & 0.03 \\
\hline & 3001 & Random & 0.11 & 0.02 \\
\hline & 3002 & Random & 0.26 & 0.06 \\
\hline \multirow{2}{*}{ ঠ্ণ } & 4001 & Random & 0.10 & 0.03 \\
\hline & 4002 & Random & 0.21 & 0.05 \\
\hline \multirow{2}{*}{$\begin{array}{l}8 \\
\text { ஜ } \\
\text { ஜ }\end{array}$} & 5001 & Random & 0.10 & 0.03 \\
\hline & 5002 & Random & 0.21 & 0.05 \\
\hline \multirow{2}{*}{ ஓ } & 6001 & Random & 0.11 & 0.03 \\
\hline & 6002 & Random & 0.19 & 0.05 \\
\hline
\end{tabular}

These low amplitude shakings allow evaluating the influence of the different parameters on the dynamic properties of the nonstructural components in terms of natural frequency The root mean square of the performed tests are compliant with the value suggested by FEMA 461 [35], i.e. $0.05 \mathrm{~g} \pm 0.01 \mathrm{~g}$.

Sine-sweep tests are also carried out; the outcome of such tests, which match the results of random vibration tests, are omitted in this paper for the sake of brevity.

The transfer curve method is adopted to evaluate the natural frequency of the different components. The method is applied for the two cabinets, the desk and the monitor. When evaluating the natural frequency of the monitor, the acceleration time history recorded on the desk is used as input and the acceleration time history recorded on the top of the monitor is used as output in the transfer curve method.

The natural frequencies for the different random tests are summarized in Table IV. It is worth noting that the monitor is identified only during tests 1000 . The results related to the first three test groups should be investigated separately from the results related to the last three test groups, due to the different input motion direction on the components (see Section 2.3).

Table IV. Natural frequency of the tested components for the different random test groups.

\begin{tabular}{ccccc}
\hline Test group ID & $\begin{array}{c}\text { double-window } \\
\text { cabinet }\end{array}$ & $\begin{array}{c}\text { single-window } \\
\text { cabinet }\end{array}$ & Desk & Monitor \\
\hline 1000 & $6.25 \mathrm{~Hz}$ & $7.03 \mathrm{~Hz}$ & $20.31 \mathrm{~Hz}$ & $7.03 \mathrm{~Hz}$ \\
\hline 2000 & $5.08 \mathrm{~Hz}$ & $6.64 \mathrm{~Hz}$ & $20.31 \mathrm{~Hz}$ & - \\
\hline 3000 & $6.25 \mathrm{~Hz}$ & $7.03 \mathrm{~Hz}$ & $20.70 \mathrm{~Hz}$ & - \\
\hline 4000 & $4.69 \mathrm{~Hz}$ & $7.03 \mathrm{~Hz}$ & $5.08 \mathrm{~Hz}$ & - \\
\hline 5000 & $5.08 \mathrm{~Hz}$ & $8.20 \mathrm{~Hz}$ & $5.08 \mathrm{~Hz}$ & - \\
\hline 6000 & $4.30 \mathrm{~Hz}$ & $7.81 \mathrm{~Hz}$ & $5.08 \mathrm{~Hz}$ & - \\
\hline
\end{tabular}

- Especially for the double-window cabinet, the natural frequency is not significantly affected by the mass amount and arrangement. It is noted that the results and comparison among test 
groups 1000, 2000 and 3000 are affected by the progressive damage of the components; indeed, the components are replaced only before test group 4000.

- The results related to the desk, which is not influenced by the different mass arrangement in the cabinets, show an almost constant natural frequency; the natural frequency is slightly larger than $20 \mathrm{~Hz}$ in the transversal direction and about $5 \mathrm{~Hz}$ in the longitudinal direction. The results are also validated by means of a numerical model in SAP 2000 [31], that is omitted for sake of brevity.

\subsection{Test results}

Earthquake shakings are performed according to the test program described in Section 2.3. After each test the compatibility of the spectrum of the recorded acceleration time-history with the required target response spectrum according to AC156 is verified. The compatibility is ensured in the frequency range between $1.3 \mathrm{~Hz}$ and $33.3 \mathrm{~Hz}$. In Figure 8 the spectrum compatibility check is shown for test 101 , corresponding to a SDS value equal to $0.15 \mathrm{~g}$.

Test 101

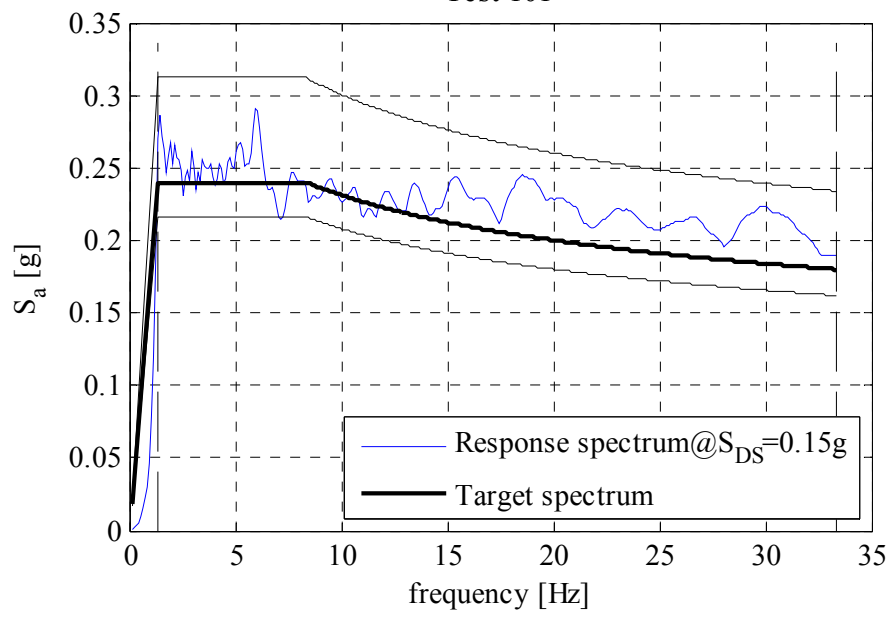

Figure 8 . Spectrum compatibility between the spectrum of the recorded acceleration time-history and the target spectrum for test 101 , corresponding to a $S_{D S}$ value equal to $0.15 \mathrm{~g}$.

In Table V and Table VI the peak shake table acceleration (or peak floor acceleration, PFA) that causes the rocking mechanism initiation and the overturning, respectively, in both the cabinets is reported. The video recordings confirm the results of the "visual" damage detection. As expected, in test groups $400-500-600$, in which the cabinets are shaken along their longitudinal direction, a larger peak floor acceleration is required in order to let the rocking mechanism develop in the single-window cabinet; the double-window cabinet, instead, does not exhibit the rocking behavior at all, exhibiting a sliding-dominated motion in the same test groups. Moreover, the overturning of the cabinet is recorded only in case the cabinets are shaken along their transversal direction. 
Table V. Peak floor acceleration (PFA) that causes the rocking mechanism initiation for the different test groups and for the two tested cabinets.

\begin{tabular}{ccc}
\hline Rocking & single-window cabinet & double-window cabinet \\
\hline Test group & PFA [g] & PFA [g] \\
\hline 100 & 0.37 & 0.48 \\
\hline 200 & 0.49 & 0.49 \\
\hline 300 & 0.49 & 0.61 \\
\hline 400 & 0.74 & \\
\hline 500 & 0.95 & \\
\hline 600 & 0.84 & \\
\hline
\end{tabular}

Table VI. Peak floor acceleration (PFA) that causes the cabinet overturning for the different test groups and for the two tested cabinets.

\begin{tabular}{ccc}
\hline Overturning & single-window cabinet & double-window cabinet \\
\hline Test group & $\underline{\text { PFA }[\mathrm{g}]}$ & $\underline{\text { PFA [g] }}$ \\
\hline 100 & 1.10 & 1.24 \\
\hline 200 & 1.24 & 0.97 \\
\hline 300 & 1.10 & \\
\hline 400 & & \\
\hline 500 & & \\
\hline 600 & & \\
\hline
\end{tabular}

Recorded maximum acceleration on the components is also correlated to the peak shake table acceleration. In Figure 9 the ratio between the peak component acceleration and the peak shake table acceleration, i.e. the component amplification, is plotted versus the peak shake table acceleration. It can thus be argued that:

- The component amplification is in the range between 2 and 3 for low intensity shakings, i.e. peak shake table acceleration less than $0.3 \mathrm{~g}$.

- As the shake table input intensity increases, several spikes are recorded in the component acceleration time histories and, consequently, the component amplification increases; the spikes are caused by the rocking behavior of the component; obviously, the spikes are larger for larger amplitude rocking mechanism.

- In test groups $100-200-300$ the rocking amplitude is large enough to induce spikes in the acceleration time histories for a peak shake table acceleration equal to $0.5 \mathrm{~g}$; this phenomenon is clearly visible for the single-window cabinet (Figure 9b).

- The cabinets low component amplification values, detected in test groups $400-500-600$, denote the small amplitude of the rocking behavior in the cases in which the cabinets are shaken along their longitudinal direction. Indeed, the component amplification values is below 4 for the different shakings.

- The desk component amplification is larger for low-to-moderate intensity shakings; as the peak floor acceleration exceeds the $0.5 \mathrm{~g}$ value, the desk slides on the floor reducing the component acceleration; in the last tests of 200 and 300 test groups, the hammering of the desk with the cabinet is clearly recorded in the acceleration time history with a large amplitude spike. 


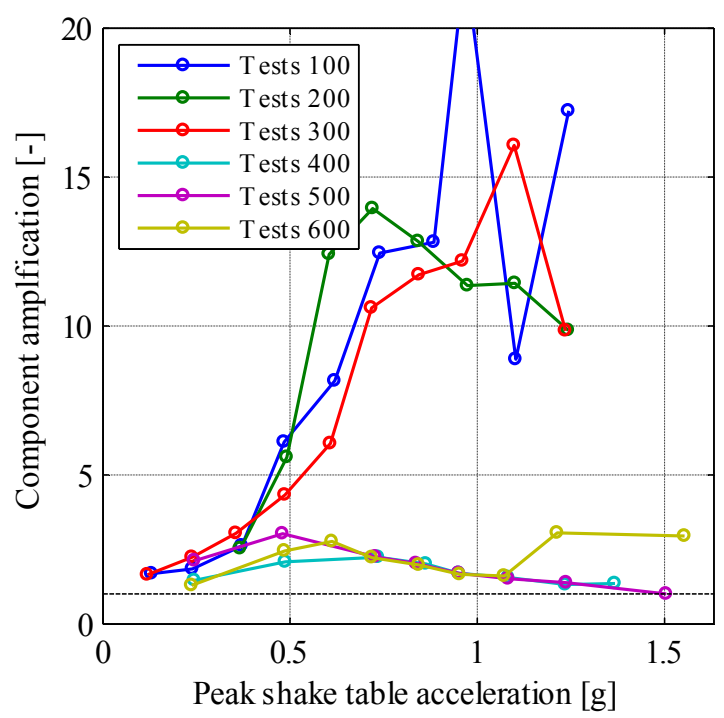

(a)

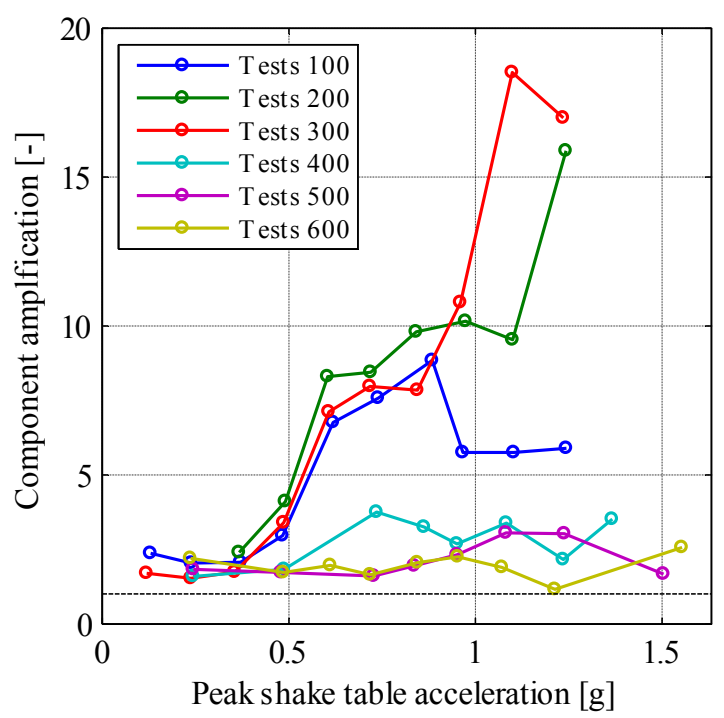

(b)

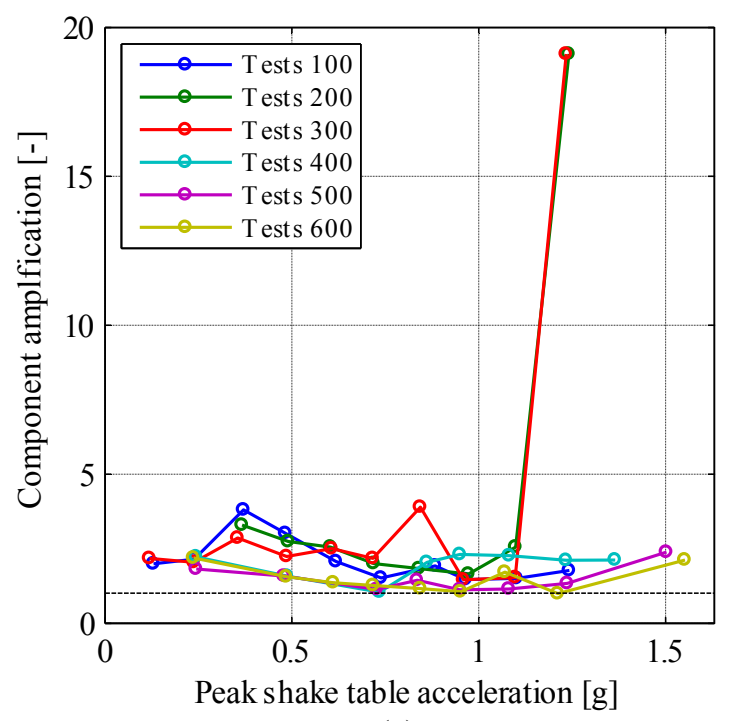

(c)

Figure 9. Ratio between peak component acceleration and peak shake table acceleration in (a) large cabinet, (b) small cabinet and (c) desk.

The rocking mechanism of the cabinets can be caught in vertical acceleration time histories recorded in the different components. For instance, in Figure 10 the vertical acceleration time history at the base of the single-window cabinet is recorded for the different tests of the test group 100. The rocking initiation in test 103 can be easily correlated to the record of few spikes. The spike amplitude becomes larger when the intensity of the input motion increases. 

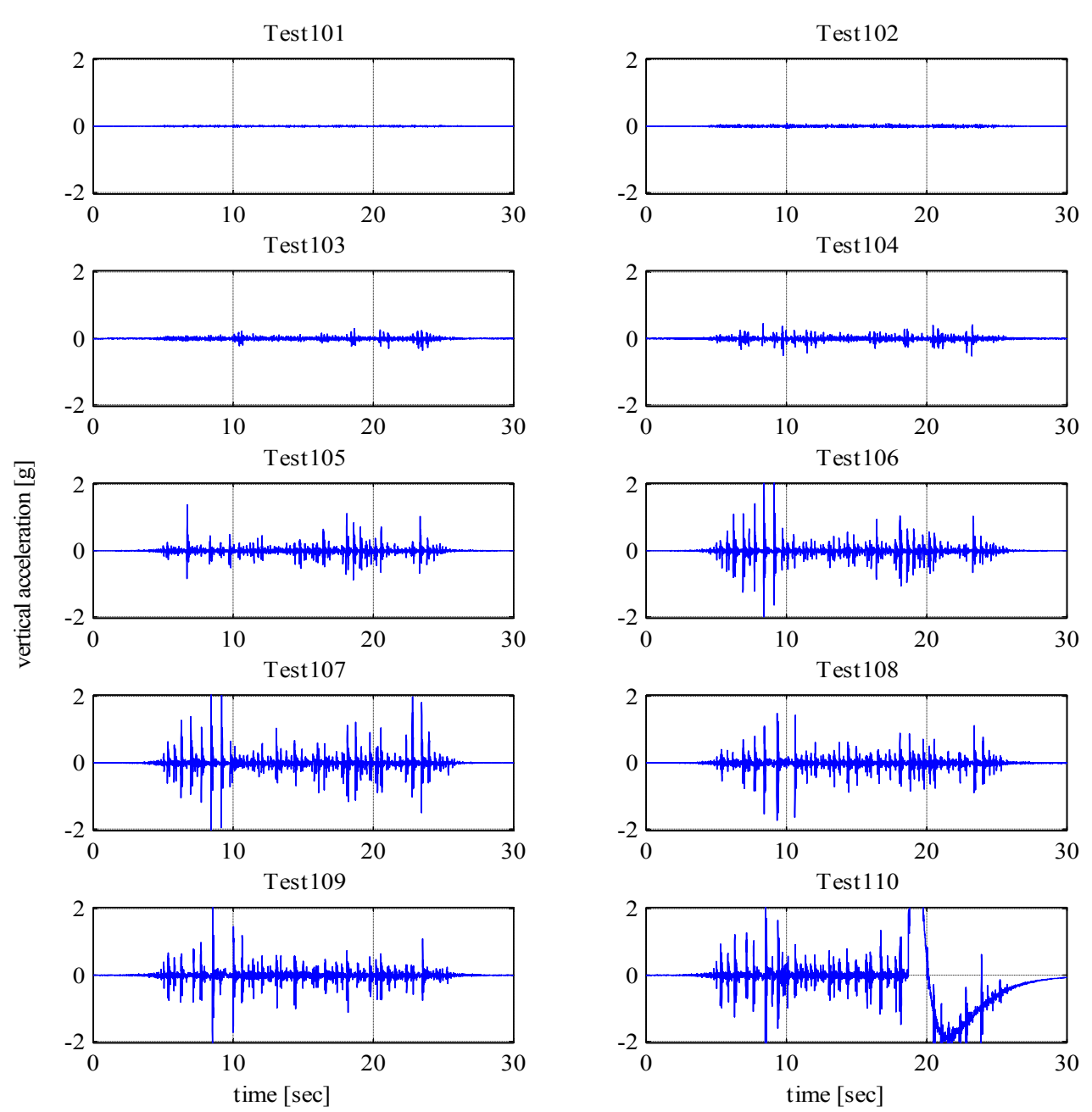

Figure 10. Vertical acceleration time history recorded at the base of the single-window cabinet for the different tests of the test group 100.

The effects of the vertical component of the ground motion have been ignored in this study. Notwithstanding, it is expected that such an effect does not remarkably influence the dynamic response of the components, e.g. the cabinets, due to their slenderness.

\subsection{Fragility curve evaluation}

As shown in Section 2.2, the input motion is unidirectional. In order to correlate the chosen engineering demand parameter, i.e. peak floor acceleration (PFA), to the three defined damage states, the results of the test groups 100, 200 and 300 are combined with the results of the test groups 400, 500 and 600. For instance, the PFA that causes the DS1 threshold is the minimum between the PFA that induces DS1 in test groups 100 and the PFA that induces DS1 in test groups 400. It is assumed that the simultaneous combined effects of the two orthogonal motions are neglected.

Given this assumption in Table VII the PFA values that trigger the different damage states for the different test groups are reported. It should be noted that DS2 PFA values are omitted. This is due to the fact that DS2 is recorded only in tests 300-600 for the overturning of some contents that are inserted in the cabinets, corresponding to a PFA equal to $0.486 \mathrm{~g}$. In tests $100-400$ and 200-500, in which sand equivalent masses are inserted in the cabinets, damage state 2 is not recorded at all, i.e. the specimen directly moves from DS1 to DS3. Hence, experimental data are not sufficient to evaluate the DS2 fragility curve. 
Table VII. Peak floor accelerations that induces damage state 1 (DS1) and damage state 3 (DS3) for the different test groups.

\begin{tabular}{ccc}
\hline Test group & DS1 & DS3 \\
\hline $100-400$ & $0.371 \mathrm{~g}$ & $1.103 \mathrm{~g}$ \\
\hline $200-500$ & $0.491 \mathrm{~g}$ & $0.974 \mathrm{~g}$ \\
\hline $300-600$ & $0.486 \mathrm{~g}$ & $1.099 \mathrm{~g}$ \\
\hline
\end{tabular}

Based upon the data in Table VII, the fragility curve is evaluated according to Porter et al. [36]. According to this procedure, the fragility parameters are computed as:

$$
\begin{gathered}
x_{m}=\exp \left(\frac{1}{M} \cdot \sum_{i=1}^{M} \ln r_{i}\right) \\
\beta_{\mathrm{mod}}=\sqrt{\frac{1}{M-1} \sum_{i=1}^{M}\left(\ln \left(r_{i} / x_{m}\right)\right)^{2}+\beta_{u}^{2}}=\sqrt{\beta_{f i t}^{2}+\beta_{u}^{2}}
\end{gathered}
$$

where $M$ is the number of the tested specimen, $r_{i}$ is the the peak floor acceleration (PFA) at which a given damage state occurs in the $\mathrm{i}$-th specimen and $\beta_{u}$, equal to 0.25 , takes into account that the specimens are subjected to the same loading history and the number of the tested specimen is less than 5 [37]. The fragility curves that fit the experimental data (dotted thick lines in Figure 11) are clearly evidenced with respect to the ones with the larger dispersion (solid thick lines in Figure 11). The latter also take into account the logarithmic standard deviation $\beta_{u}$. As expected, $\beta_{f i t}$ is very small, since it includes only the variability due to the different mass configuration.

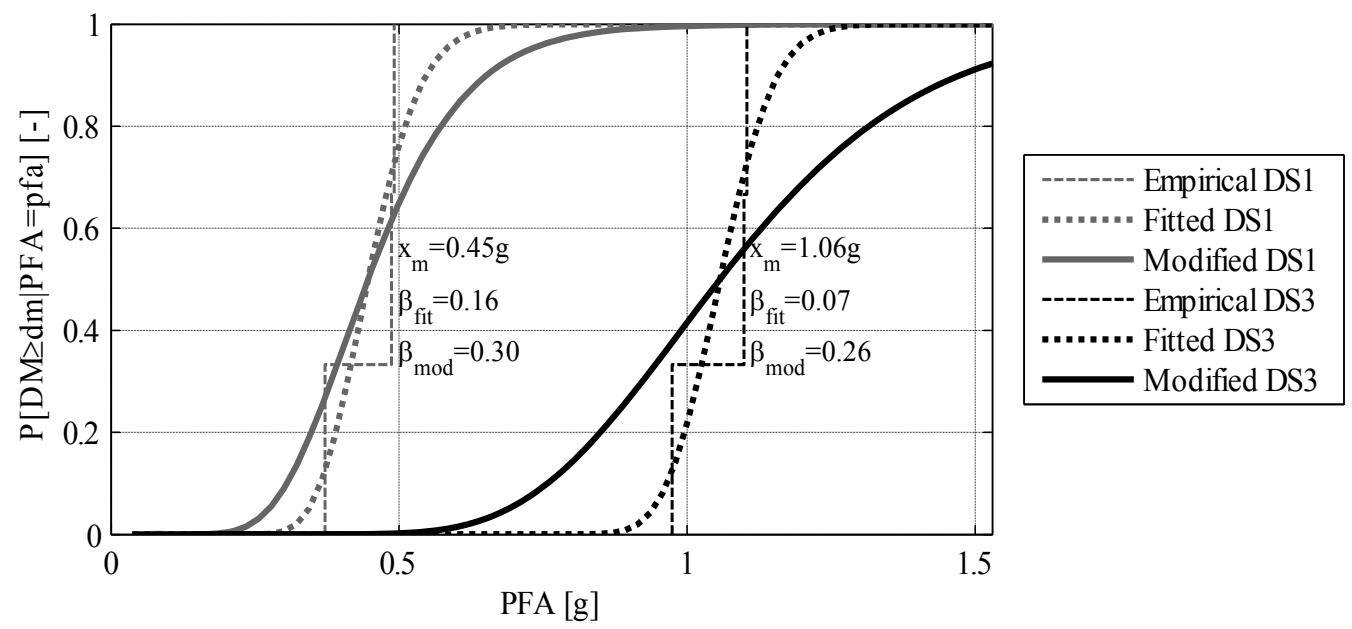

Figure 11. Fragility curves for the damage states 1 and 3 considering mass variability.

In order to evaluate the influence that the distance between the cabinet and the wall has on the seismic response of the cabinet, the fragility curve is evaluated considering the data related to test groups 110 and 120. PFA values that cause DS3 are $0.738 \mathrm{~g}$ and $0.851 \mathrm{~g}$ for test groups 110 and 120 , respectively. Considering a group that includes the DS3 PFA values for test groups 100, 110 and 120, a fragility curve that takes into account the randomness due to different wall-to-cabinets distances can be evaluated (gray lines in Figure 12). In Figure 12 this fragility curve is compared to the one that takes into account the mass variability (Figure 11). It can be observed that the gap variability significantly decreases the DS3 median value that moves from $1.06 \mathrm{~g}$ to $0.89 \mathrm{~g}$. This confirms the observation included in [38] that the larger the wall-to-cabinets/bookcase distance, the higher the probability that it would overturn. 


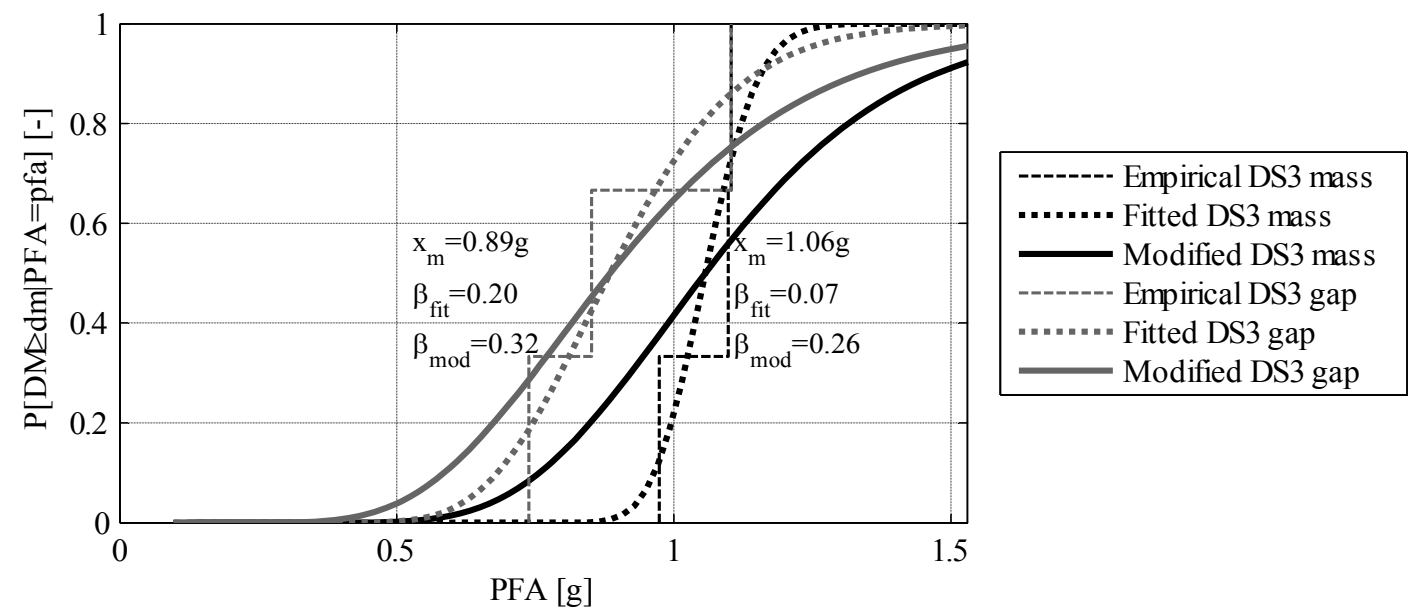

Figure 12. Fragility curves evaluated considering gap and mass variability for the damage state 3 .

Finally, considering the five experimental DS3 data, related to test groups 100-400, 110, 120, 200500 and 300-600, a fragility curve (dotted thick line in Figure 13) that takes into account both mass and gap variability can be evaluated. The DS3 fragility curve that includes also the $\beta_{u}$ standard deviation is then evaluated (solid thick line in Figure 13). This fragility curve satisfies the Lilliefors goodness-of-fit test [39]; a 5\% confidence level is adopted.

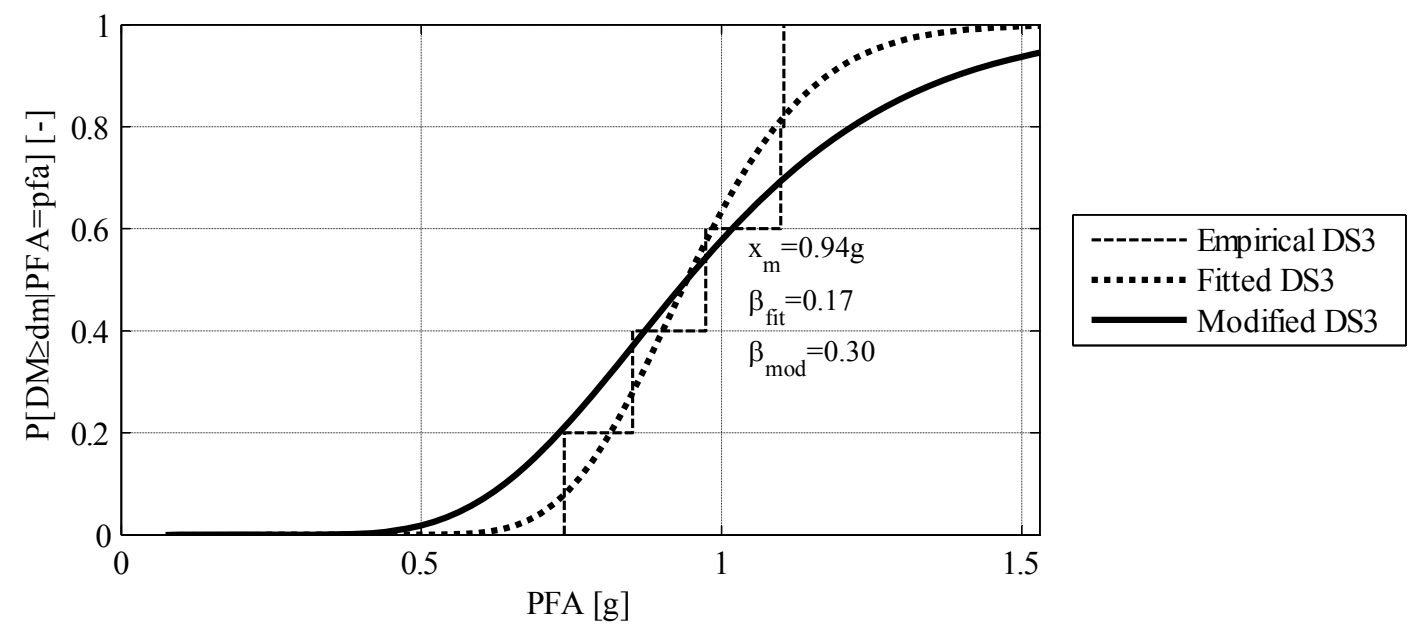

Figure 13. Fragility curves evaluated considering both gap and mass variability in the same experimental data for the damage state 3 .

\section{CONCLUSIONS}

The research study presented in the present paper is motivated by the urgent needs to further investigate the seismic performance of medical equipment and typical hospital components. The preliminary results of shake table tests on a full-scale laboratory room unit equipped with typical architectural finishing, freestanding furniture items, desktop computer and medical equipment are discussed.

An examination (out patients consultation) room is selected as representative layout for the experimental seismic performance assessment of the core units of hospital buildings. The building contents utilized for the examination room include two cabinets, a desktop computer and a desk; different glass contents are also included in the cabinets in some tests. Different mass distributions 
are selected to distribute such contents in the single- and double-window cabinets. 63 shakings are performed during the whole test campaign.

- The natural frequency of the different components is estimated. It is found that the distribution of the mass along the height assumes a key role to evaluate the natural frequency of the cabinets in case they are shaken along their transversal direction.

- The peak shake table acceleration (PFA) that causes the rocking mechanism initiation and the overturning, respectively, in both the cabinets are analyzed. In particular, the rocking mechanism in the two tested specimens initiates for a PFA that ranges between $0.37 \mathrm{~g}$ and $0.61 \mathrm{~g}$; instead the overturning of the cabinets occurs for PFA slightly larger than $1.00 \mathrm{~g}$.

- The accelerations recorded at the top of the different components are strictly related to rocking phenomenon, that induces spikes in the recorded time-histories. It is noted that as the peak floor acceleration exceeds the $0.5 \mathrm{~g}$ value, the desk slides on the floor reducing the acceleration recorded on the component.

- By investigating the vertical acceleration time histories recorded on the cabinets, it is concluded that the rocking mechanism of the cabinets can be easily caught in these time histories.

- A damage scheme is defined in order to correlate the visual damage to the onset of the selected three-stage damage states in the hospital examination room. Fragility curves are defined for damage state 1 and damage state 3 . Such fragility are derived based on a systemic approach, i.e. encompassing the performance levels of the components within the sample examination rooms. Different groups of specimens are considered in the evaluation of the fragility curves in order to investigate the mass variability, cabinet-to-wall distance variability and both mass and cabinet-to-wall distance variability. It is emphasized that the cabinet-to-wall distance increase can significantly reduce the seismic performance of the cabinets. This confirms that the higher the wall-to-cabinets/bookcase distance, the higher the probability of the overturn of the component.

\section{ACKNOWLEDGMENTS}

The research study has been funded by the Italian Department of Civil Protection in the frame of the national project DPC - ReLUIS 2010-2013, Task 2.2.2, Vulnerability and risk assessment of health care facilities. The authors would like to acknowledge Siniat that provided the ceiling and the partitions used in the testing program. The anonymous reviewers are also acknowledged; their valuable comments and suggestions have significantly improved the manuscript.

\section{APPENDIX}

This Section reports the damage table that the inspector compiles after each shake table test. The table collects the main experimental outcomes. The occurrence of different damage to the different components is reported. The permanent displacement along the two horizontal directions (graphically defined on the ground floor) of two edges of the cabinets and of the desk are also measured. The portion of glass contents that exhibits a certain type of damage is also described. In Table VIII the damage table compiled after test no. 308, corresponding to a $1.20 \mathrm{~g}$ SDs value, is reported. The data collected in the damage table are then compared to the damage scheme (Table II) for the evaluation of the occurred Damage State, i.e. DS1, DS2 or DS3, in the tested specimen. 
Table VIII. Damage table compiled after test no. 308.

\begin{tabular}{|c|c|c|c|c|c|c|c|c|}
\hline \multicolumn{2}{|c|}{$\begin{array}{l}\text { TEST IDENTIFICATION } \\
\end{array}$} & & \multicolumn{5}{|c|}{ I- CABINETS } & \\
\hline Test group & 300 & & \multicolumn{5}{|c|}{$2 \mathrm{~W}$ indows $1 \mathrm{~W}$ indow } & \\
\hline ID Test & 308 & & \multicolumn{3}{|c|}{ Displacement (P1) X [cm] } & 0 & 2.5 & \\
\hline Date & $15 J u l y$ & & \multicolumn{3}{|c|}{ Displacement (P1) Y [cm] } & -1 & -0.3 & \\
\hline \multirow[t]{5}{*}{ Time } & $17: 51$ & & \multicolumn{3}{|c|}{ Displacement (P2) X [cm] } & $o$ & 2.5 & \\
\hline & & & \multicolumn{3}{|c|}{ Displacement (P2) Y [cm] } & -1 & -0.3 & \\
\hline & & & \multicolumn{3}{|c|}{ Window damage } & no & no & \\
\hline & & & \multicolumn{3}{|c|}{ Rocking } & yes & yes & \\
\hline & & & \multicolumn{3}{|c|}{ Overturning } & no & no & \\
\hline \multicolumn{4}{|c|}{ II - DRIP-FEED SUPPORT } & & \multicolumn{3}{|c|}{ III - MONITOR } & \\
\hline \multicolumn{3}{|c|}{ Sliding } & \multicolumn{2}{|l|}{ yes } & \multicolumn{2}{|c|}{ Sliding } & no & \\
\hline \multicolumn{3}{|c|}{ Overturning } & \multicolumn{2}{|l|}{ no } & \multicolumn{2}{|c|}{ Overturning } & yes & \\
\hline \multicolumn{3}{|c|}{ Collapse } & no & & \multicolumn{2}{|c|}{ Switch off } & no & \\
\hline \multicolumn{4}{|c|}{ IV - DESK } & & \multicolumn{3}{|c|}{ V - NEGATIVOSCOPE } & \\
\hline \multicolumn{3}{|c|}{ Sliding } & yes & & \multicolumn{2}{|c|}{ Damage } & no & \\
\hline \multicolumn{3}{|c|}{ Drawer opened } & yes & & \multicolumn{2}{|c|}{ Collapse } & no & \\
\hline \multicolumn{3}{|c|}{ Displacement $(\mathrm{P} 1) \mathrm{X}[\mathrm{cm}]$} & 6 & & \multicolumn{2}{|c|}{ Switch off } & no & \\
\hline \multicolumn{3}{|c|}{ Displacement (P1) Y [cm] } & -10 & & & & & \\
\hline \multicolumn{3}{|c|}{ Displacement $(\mathrm{P} 2) \mathrm{X}[\mathrm{cm}]$} & 4 & & & & & \\
\hline Displac & cement (P2) & $\mathrm{cm}]$ & 8 & & & & & \\
\hline & & & & I-GLAS & CONTE & & & \\
\hline & Doub & window & inet & & & le-window c & binet & \\
\hline & Bottle & Bottle & Bottle & Flask & Flask & Test tube & Beaker & Beaker \\
\hline & $500 \mathrm{ml}$ & $250 \mathrm{ml}$ & $100 \mathrm{ml}$ & $250 \mathrm{ml}$ & $100 \mathrm{ml}$ & dock & $250 \mathrm{ml}$ & $100 \mathrm{ml}$ \\
\hline Sliding & $12 / 12$ & $8 / 8$ & $8 / 8$ & $8 / 8$ & $8 / 8$ & $4 / 4$ & $4 / 4$ & $4 / 4$ \\
\hline Overturning & $1 / 12$ & $3 / 8$ & $5 / 8$ & $0 / 8$ & $0 / 8$ & $2 / 4$ & $0 / 4$ & $0 / 4$ \\
\hline Damage & $0 / 12$ & $0 / 8$ & $0 / 8$ & $0 / 8$ & $0 / 8$ & $0 / 4$ & $0 / 4$ & $0 / 4$ \\
\hline
\end{tabular}

\section{REFERENCES}

[1] Bozorgnia Y, Bertero VV. Earthquake Engineering From Engineering Seismology to Performance-Based Engineering. CRC PRESS: Boca Raton, Florida, USA, 2004.

[2] Miranda E, Aslani H. Building-specific loss estimation methodology. PEER Report No.2003-03. Pacific Earthquake Engineering Research Center: University of California at Berkeley, Berkeley, California, 2003.

[3] Taghavi S, Miranda E. Response assessment of nonstructural building elements, PEER report 2003/05. College of Engineering, University of California Berkeley, USA, 2003.

[4] World Health Organization (WHO). Risk reduction in the Health Sector and Status of Progress. Proceedings of the Disaster Risk Reduction in the Healthcare Sector - Thematic Workshop: Geneva, Switzerland, 2007.

[5] Gunn SWA. Health effects of earthquakes. Disaster Prevention and Management 1995; 4 (5): 6-10.

[6] Pinto PE, Lupoi A, Franchin P. Deliverable D.2.8 - Definition of system components and the formulation of system function to evaluate the performance of critical facilities. SYNER-G project: Systemic Seismic Vulnerability and Risk Analysis for Buildings, Lifeline Networks and Infrastructures Safety Gain: University of Rome "La Sapienza", Rome, Italy, 2011.

[7] Federal Emergency Management Agency (FEMA). Design Guide for Improving Hospital Safety in Earthquakes, Floods and High Winds. Report No. FEMA 577. Washington D.C., USA, 2007. 
[8] Achour N, Miyajima M, Kitaura M, Price A. Earthquake-Induced Structural and Nonstructural Damage in Hospitals. Earthquake Spectra 2011; 27 (3): 617-634. DOI:10.1193/1.3604815.

[9] Di Sarno L, Yenidogan C, Erdik M. Field evidence and numerical investigation of the Mw= 7.1 October 23 Van, Tabanl1 and the $\mathrm{Mw}>5.7$ November earthquakes of 2011. Bulletin of Earthquake Engineering 2013; 11 (1): 313-346. DOI:10.1007/s10518-012-9417-0.

[10] McIntosh JK, Jacques C, Mitrani-Reiser J, Kirsch TD, Giovinazzi S, Wilson TM. The Impact of the 22nd February 2011 Earthquake on Christchurch Hospital. 13-15 April 2012, Christchurch, New Zealand, 2012.

[11] Sato E, Furukawa S, Kakehi A, Nakashima M. Full-scale shaking table test for examination of safety and functionality of base-isolated medical facilities. Earthquake Engineering \& Structural Dynamics 2011; 40 (13): 1435-1453. DOI:10.1002/Eqe.1097.

[12] Furukawa S, Sato E, Shi Y, Becker T, Nakashima M. Full-scale shaking table test of a baseisolated medical facility subjected to vertical motions. Earthquake Engineering \& Structural Dynamics 2013; 42 (13): 1931-1949. DOI:10.1002/eqe.2305.

[13] Kuo K-C, Suzuki Y, Katsuragi S, Yao GC. Shake table tests on clutter levels of typical medicine shelves and contents subjected to earthquakes. Earthquake Engineering \& Structural Dynamics 2011; 40 (12): 1367-1386. DOI:10.1002/eqe.1094.

[14] Mosqueda G, Retamales R, Filiatrault A, Reinhorn A. Testing Facility for Experimental Evaluation of Non-Structural Components under Full-Scale Floor Motions. Structural Design of Tall and Special Buildings 2009; 18 (4): 387-404. DOI:10.1002/Tal.441.

[15] Chen M, Pantoli E, Wang X, Espino E, Mintz S, Conte J, Hutchinson T, Marin C, Meacham B, Restrepo J, Walsh K, Englekirk R, Faghihi M, Hoehler M. Design and Construction of a Full-Scale 5-Story Base Isolated Building Outfitted with Nonstructural Components for Earthquake Testing at the UCSD-NEES Facility. ASCE Structures Congress 2012: Chicago, IL, US, 2012.

[16] Comerio M. PEER Testbed Study on a Laboratory Building: Exercising Seismic Performance Assessment. PEER Report No. 2005/12. Pacific Earthquake Engineering Research Center: College of Engineering, University of California, Berkeley, California, USA, 2005.

[17] Konstantinidis D, Makris N. Experimental and analytical studies on the response of freestanding laboratory equipment to earthquake shaking. Earthquake Engineering \& Structural Dynamics 2009; 38 (6): 827-848. DOI:10.1002/Eqe.871.

[18] Porter K, Johnson G, Zadeh M, Scawthorn C, Eder S. Seismic Vulnerability of Equipment in Critical Facilities: Life-Safety and Operational Consequences. Technical Report NCEER93-0022. State University of New York at Buffalo, NY, US, 1993.

[19] Johnson GS, Sheppard RE, Quilici MD, Eder JE, Scawthorn CR. Seismic Reliability Assessment of Critical Facilities: A Handbook, Supporting Documentation, and Model Code Provisions. Technical Report MCEER-99-0008. University at Buffalo, NY, US, 1999.

[20] Achour N. Estimation of malfunction of a healthcare facility in case of earthquake. PhD Thesis. Kanazawa University, Kanazawa, Japan, 2007.

[21] Zhang J, Makris N. Rocking Response of Free-Standing Blocks under Cycloidal Pulses. Journal of Engineering Mechanics 2001; 127 (5): 473-483. DOI:doi:10.1061/(ASCE)07339399(2001)127:5(473).

[22] Tokas C. California's Hospital Seismic Retrofit Program. Symposium on Seismic Regulations and Challenges for Protecting Building Equipment, Components and Regulations: University at Buffalo, Buffalo, US, 2007.

[23] California Building Standards Commission (CSBC). California Building Code. Sacramento. CA, US, 2007. 
[24] Office of Statewide Health Planning and Development (OSHPD). SB 1953 Regulations (2007), Title 24, Part 1, California Building Standards Administrative Code. OSHPD: State of California, US, 2007.

[25] American Society of Civil Engineers. ASCE/SEI 7-10: Minimum Design Loads for Buildings and Other Structures. Reston, Virginia, US, 2010.

[26] Magliulo G, Petrone C, Capozzi V, Maddaloni G, Lopez P, Manfredi G. Seismic performance evaluation of plasterboard partitions via shake table tests. Bulletin of Earthquake Engineering 2014 (online first). DOI:10.1007/s10518-013-9567-8.

[27] Petrone C, Magliulo G, Manfredi G. Shake table tests for the seismic assessment of hollow brick internal partitions. Engineering Structures 2014 (under review).

[28] Aiello A, Pecce M, Di Sarno L, Perrone D, Rossi F. A safety index for hospital buildings. Disaster Advances 2012; 5 (4): 270-277.

[29] Myrtle RC, Masri SE, Nigbor RL, Caffrey JP. Classification and prioritization of essential systems in hospitals under extreme events. Earthquake Spectra 2005; 21 (3): 779-802. DOI:10.1193/1.1988338.

[30] Magliulo G, Pentangelo V, Maddaloni G, Capozzi V, Petrone C, Lopez P, Talamonti R, Manfredi G. Shake table tests for seismic assessment of suspended continuous ceilings. Bulletin of Earthquake Engineering 2012; 10 (6): 1819-1832. DOI:10.1007/s10518-0129383-6.

[31] CSI Computer \& Structures Inc. SAP2000. Linear and Nonlinear Static and Dynamic Analysis of Three-Dimensional Structures, Computer \& Structures, Inc. Berkeley, California, 2004.

[32] International Conference of Building Officials (ICBO). AC 156 Acceptance Criteria for the Seismic Qualification of Nonstructural Components. ICBO Evaluation Service, Inc., Whittier, California, USA, 2000.

[33] Hancock J, Watson-Lamprey J, Abrahamson NA, Bommer JJ, Markatis A, McCoyh E, Mendis R. An improved method of matching response spectra of recorded earthquake ground motion using wavelets. Journal of Earthquake Engineering 2006; 10 (sup001): 6789. DOI:10.1080/13632460609350629.

[34] Magliulo G, Petrone C, Capozzi V, Maddaloni G, Lopez P, Talamonti R, Manfredi G. Shake Table Tests on Infill Plasterboard Partitions. The Open Construction and Building Technology Journal 2012; 6 (Suppl 1-M10): DOI:10.2174/1874836801206010155.

[35] Federal Emergency Management Agency (FEMA). Interim protocols for determining seismic performance characteristics of structural and nonstructural components through laboratory testing. Report No. FEMA 461. Washington DC, US, 2007.

[36] Porter K, Kennedy R, Bachman R. Creating Fragility Functions for Performance-Based Earthquake Engineering. Earthquake Spectra 2007; 23 (2): 471-489. DOI:10.1193/1.2720892.

[37] Porter K, Kennedy R, Bachman R. Developing Fragility Functions for Building Components for ATC-58. A Report to ATC-58. Applied Technology Council, Redwood City, CA, US, 2006.

[38] Filiatrault A, Kuan S, Tremblay R. Shake table testing of bookcase - partition wall systems. Canadian Journal of Civil Engineering 2004; 31 (4): 664-676. DOI:10.1139/104-031.

[39] Lilliefors HW. On the Kolmogorov-Smirnov Test for Normality with Mean and Variance Unknown. Journal of the American Statistical Association 1967; 62 (318): 399-402. DOI:10.2307/2283970. 